\title{
Risk factors associated with underweight status in children under five: an analysis of the 2010 Rwanda Demographic Health Survey (RDHS)
}

Assumpta Mukabutera ${ }^{* *}$, Dana R. Thomson ${ }^{1,2}$, Bethany L. Hedt-Gauthier ${ }^{1,2,3}$, Paulin Basinga ${ }^{1,4,5}$, Laetitia Nyirazinyoye ${ }^{1}$ and Megan Murray ${ }^{2,6}$

\begin{abstract}
Background: Under-nutrition contributes to childhood morbidity and mortality, particularly in low-income countries. While Rwanda is one of few countries on track to reduce the prevalence of underweight children under five years old by 50 \% from 1990 to 2015 (a target of Millennium Development Goal1), underweight children remain a large public health problem with one out of ten children having low weight-for-age.
\end{abstract}

Methods: We performed a cross-sectional study using 2010 RDHS data on 4177 children under five years of age with weight and height measurements. Children were classified as underweight if their weight-for-age Z scores (WAZs) were $<2$ standard deviations (SD) and severely underweight if WAZs were $<3$ SD from the mean of the reference population. We used multivariable logistic regression model to identify child, maternal, and household characteristics associated with being underweight.

Results: Eleven percent (469) of the 4177 children sampled were underweight and $2.2 \%$ (90) were severely underweight. After adjusting for possible confounders, we found that children were more likely to be underweight if they were male $(\mathrm{OR}=1.42,95 \%$ confidence interval $(\mathrm{Cl}): 1.12,1.79)$; had fever in the two weeks prior to survey administration $(\mathrm{OR}=1.45,95 \% \mathrm{Cl}: 1.07,1.97)$ or were non-singletons compared to first-born singletons $(\mathrm{OR}=4.04,95 \%$ $\mathrm{Cl}: 2.12,7.71)$. Mothers were more likely to have underweight children if they were over 35 years of age compared to those age 17-24 years ( $\mathrm{OR}=1.67,95 \% \mathrm{Cl}: 1.04,2.70)$; with $\mathrm{BMl}<18.5$ compared to $\mathrm{BMl}$ between 18.5 to $24.9(\mathrm{OR}=2.62$, $95 \% \mathrm{Cl}: 1.70,4.04)$, who had no education or primary education only (OR=3.56, $95 \% \mathrm{Cl}: 1.83,6.95 ; \mathrm{OR}=3.49$, $95 \% \mathrm{Cl}: 1$. $87,6.51$, respectively) compared to secondary education or higher, and those who did not have delivery assisted by a skilled provider ( $\mathrm{OR}=1.33,95 \% \mathrm{Cl}: 1.04,1.72)$. Household characteristics associated with underweight children included status in the bottom two wealth quintiles compared to the highest $(\mathrm{OR}=1.71,95 \% \mathrm{Cl}: 1.27,2.30)$.

Conclusion: Rwanda was one of the first countries to achieve Millennium Development Goal1. However, even in light of this success, the prevalence of underweight children remains high. Our analysis of specific child, maternal and household risk factors for under-nutrition may help identify potential interventions to address this remaining burden.

Keywords: Africa, Under-nutrition, DHS, Underweight

* Correspondence: amukabutera@nursph.org

${ }^{1}$ University of Rwanda School of Public Health, P.O. Box: 3538, Kigali, Rwanda

Full list of author information is available at the end of the article 


\section{Background}

Under-nutrition remains one of the most common causes of morbidity and mortality among children under five years of age in developing countries [1]. In 2011, $16 \%$ of children under five were underweight (low weight-for-age) in developing countries and $45 \%$ of under-five deaths were directly or indirectly linked to under-nutrition [2]. Despite global improvements, the prevalence of underweight children under five is still a major public health problem in sub-Saharan Africa [2] and many countries have failed to achieve the first Millennium Development Goal (MDG 1) that called for the eradication of extreme hunger and the reduction of the prevalence of underweight children by $50 \%$ from 1990 to 2015 [3, 4].

Anthropometric indicators such as weight-for-height (wasting), height-for-age (stunting) and weight-for-age (underweight) are used to evaluate the nutrition status of children. Stunting results from chronic under-nutrition, which retards linear growth, while inadequate nutrition over a shorter period results in wasting [5]. Underweight is thought to encompass both stunting and wasting although some surveys find that a small percentage of children are underweight but do not meet the definition of either stunting or wasting. We chose to study risk factors for the primary MDG1 measurement indicator, being underweight. Although the choice of indicator for MDG 1 was controversial, a comparison of the three indicators using DHS data from Kenya suggests that underweight is reliable indicator of overall child growth [6]. Poverty is chief among the determinants of low weight-for-age, which also include household food insecurity and inadequate intake of nutrients [7], poor childcare practices, unhealthy living environments that contribute to frequent infection $[8,9]$, poor health care and maternal undernutrition leading to low birth-weight $[1,4,8]$.

Rwanda achieved MDG1 in 2010 [3], with the prevalence of under nutrition falling by $62 \%$ from $29 \%$ in 1992 [9] to $11 \%$ in 2010 [10]. Further, stunting decreased from $48 \%$ to $44 \%$ and wasting from $3.8 \%$ to $2.8 \%$ in this same time period [10]. Although results of the 2015 DHS are not yet available, further declines in undernutrition are expected to have occurred in the past five years. Despite having a low prevalence of underweight children compared to its neighboring countries, (29\% in Burundi, 24 \% in Democratic Republic of Congo and $16 \%$ in Tanzania) [3] and despite significant recent improvements, one in ten children in Rwanda was still underweight in 2010 [10]. This rate is high in comparison with developed economies, where the prevalence of underweight children is less $2.5 \%$ [11]. The DHS report provided descriptive information on the proportion of the population that was underweight but did not analyze risk factors for being underweight. We conducted this analysis to help identify potential interventions to address the problem. In this paper, we aim to identify risk factors for being underweight in the context of intensive nutrition interventions, that may be useful for informing policy and indicator-specific programming to resolve the underweight problem in order to close this gap and further reduce the prevalence of underweight children in Rwanda.

\section{Methods}

\section{Data sources}

This analysis of the 2010 Rwanda Demographic and Health Survey (RDHS) includes data on children under five years of age, their mothers and households [10]. The 2010 RDHS was a nationally representative sample of 13,671 women age 15 to 49 years from 12,540 households. The study used a two-stage cluster design, stratified by Rwanda's 30 districts. In the first stage, 492 villages were selected from a national listing of all villages with probability proportionate to the number of households in each village. In the second stage, surveyors mapped and systematically sampled every tenth household within a sampled village until the 12,540 household sample was reached. All women age 15 to 49 in selected households were invited to participate. The questionnaires were administered orally in Kinyarwanda.

In half of all households, anthropometric measurements were taken for all children under five years of age. To be eligible, children must have spent the night before the survey in the household. Child weight was measured with a lightweight electronic scale [10]. Very young children were weighed with the respondent standing on the scale and the child's weight estimated by subtracting the respondent's weight [10]. Children's ages were ascertained from mothers who supplied the date of birth. Socio-economic status was provided by DHS based on a principal components analysis of survey responses ownership of specified durable goods (television, radio, car, mobile telephone, etc.) and housing characteristics (access to electricity, source of drinking water, type of toilet facilities, type of flooring material, number of rooms used for sleeping, and type of cooking fuel).

\section{Data analysis}

We used the recorded weight and age of each child to create an underweight variable; we classified children as underweight if their weight-for-age was less than two standard deviations from the reference population and severely underweight if WAZ was less than three standard deviations, as wasted if weight-for-height was less than two standard deviations and as stunted if heightfor-age was less than two standard deviations [10]. We considered the following child, maternal and household variables as potential predictors of being underweight: a) child's gender, age in months, size at birth, birth interval 
Table 1 Socio-demographic characteristics of mothers and children under 5 years old in Rwanda DHS 2010

\begin{tabular}{|c|c|c|c|c|c|}
\hline Characteristic & $N$ (weighted) & $\%$ & Sex of the household head $(N=4,176)$ & & \\
\hline Underweight (weight-for-age $<-2$ sd) $(N=4,117)$ & & & Female & 877 & 21.0 \\
\hline No & 3708 & 88.6 & Male & 3299 & 79.0 \\
\hline Yes & 469 & 11.4 & Residence $(N=4,176)$ & & \\
\hline $\begin{array}{l}\text { Severe underweight (weight-for-age }<-3 \text { sd) } \\
(N=4,117)\end{array}$ & & & Urban & 484 & 11.6 \\
\hline No & 4027 & 97.8 & Rural & 3692 & 88.4 \\
\hline Yes & 90 & 2.2 & Wealth quintile $(N=4,176)$ & & \\
\hline Child age $(N=4,177)$ & & & Top 2 & 1480 & 35.4 \\
\hline$<12$ months & 793 & 19.0 & Middle & 848 & 20.3 \\
\hline $12-23$ months & 800 & 19.1 & Bottom 2 & 1848 & 44.2 \\
\hline 24-35 months & 900 & 21.5 & Toilet cleanness upon inspection $(N=4,159)$ & & \\
\hline $36-47$ months & 845 & 20.2 & Not cleaned & 2717 & 65.3 \\
\hline 48-59 months & 839 & 20.1 & Yes cleaned & 1442 & 34.7 \\
\hline Child sex $(N=4,176)$ & & & Quality of toilet $(N=4,075)$ & & \\
\hline Boys & 2101 & 50.3 & Unimproved shared & 203 & 5.0 \\
\hline Girls & 2075 & 49.7 & Improved shared & 575 & 14.1 \\
\hline Child size at birth $(N=4,159)$ & & & Improved not shared & 2431 & 59.7 \\
\hline Not small at birth & 3521 & 84.7 & Unimproved not shared & 866 & 21.2 \\
\hline Small at birth & 638 & 15.3 & Proximity to improved water source $(N=4,155)$ & & \\
\hline Birth interval (from previous birth) $(N=4,176)$ & & & Water on premise & 167 & 4.0 \\
\hline Singleton first-born & 1014 & 24.3 & $<30$ minutes & 1787 & 43.2 \\
\hline Singleton birth $<2$ years & 624 & 14.9 & $>=30$ minutes & 2181 & 52.7 \\
\hline Singleton birth $>=2$ years & 2437 & 58.4 & Missing & 42 & \\
\hline Multiple births & 101 & 2.4 & Water treatment $(N=4,177)$ & & \\
\hline Mother age in year $(N=4,176)$ & & & No & 2118 & 50.7 \\
\hline $15-24$ & 755 & 18.1 & Yes & 2058 & 49.3 \\
\hline $25-34$ & 2255 & 54.0 & Missing & 1 & \\
\hline $35-49$ & 1166 & 27.9 & Total & 4177 & 100 \\
\hline
\end{tabular}

Mother's highest level of educational $(N=4,176)$

No education

Primary

Secondary or higher

Mother occupation $(N=4,174)$

Not working
Skilled worker
Unskilled worker

Marital status $(N=4,174)$

Single

Married/partnered

Separated/divorced

Delivery assisted by health professional $(N=4,176)$
Table 1 Socio-demographic characteristics of mothers and children under 5 years old in Rwanda DHS 2010 (Continued)

and whether the child was a singleton, breastfeeding practice, recent deworming, diarrhea in the last two weeks and fever in the last two weeks; b) mother's age, body mass index (BMI), education, occupation, antenatal care visits during the last pregnancy, delivery assistance for the last pregnancy and smoking behavior; and c) household's urban/rural residence, number of household members, sex of the head of household, wealth quintile and sanitation characteristics including access to improved drinking water source, water treatment measures, proximity to improved water source, having an improved toilet, toilet sharing and child stool disposal. We defined improved drinking water source as water coming from a protected spring or a public tap or standpipe. We considered drinking water to have been treated if it was boiled, treated with chlorine, sand, filter or solar disinfection. We defined proximity to improved water source as having water on the premises or obtainable within a 30 min walk. 
We considered toilet facilities to be improved if they consisted of a pit latrine with a slab or a flush toilet to a piped sewer system or septic tank. We considered a shared toilet to be one that is routinely used by people other than members of the household. We considered children's stools to have been safely disposed of if the child used a toilet or latrine, if the fecal matter was put/rinsed into a toilet or latrine or if it was put into a piped sewer system/ septic tank/pit latrine or a ventilated pit latrine.

We presented the estimated relative frequencies of seven anthropometric categories by pie chart. We assessed risk factors for being underweight using univariable and multivariable logistic regression. All variables associated with being underweight in the univariable analysis at the $\alpha=0.10$ significance level were considered in the multivariable model. We also assessed whether there was an interaction between the effect of child's birth size and current age on being underweight. We developed the final multivariable model through backwards-stepwise regression. Variables were ordered by level of impact on underweight status based on previous literature and the UNICEF nutrition framework [3], and we removed variables one at a time if $p>0.05$, stopping when all remaining variables were statistically significant. We report odds ratios and corresponding $95 \%$ confidence intervals. Sampling weights were applied to all observations to compensate for over-sampling of urban respondents in the study design and analyses accounted for clustering of children within villages and sample stratification by district. We used Stata v12 (StataCorpLP; 4905 Lakeway Drive, College Station, TX, USA) for all analysis.

\section{Results}

\section{Study population description}

The final sample for this analysis included 4177 children under five years of age and their mothers. Among these, $469(11.4 \%)$ were underweight (Table 1$)$. The relative frequencies of the seven anthropometric categories were distributed as follow: $33.87 \%(n=1394)$ were only stunted, $1.05 \%(n=43)$ only wasted, $0.43 \%(n=17)$ only underweight $0.83 \%(n=34)$ underweight and wasted, $9.12 \%(n=375)$ underweight and stunted, $1.02 \%(n=$ 42) were underweight, wasted and stunted, and the remaining $53.69 \%(n=2210)$ were neither underweight, stunted, nor wasted (Fig. 1). The overlapping categories mean that there are children who are at the same time underweight and wasted or stunted (a child may be too thin for his age and being too short compared to his age and weight). Boys and girls were equally represented and $638(15.0 \%)$ were reported to be small at birth. The majority of mothers $(n=2255,54.0 \%)$ were between ages 25 and 34 years, 755 (18.0\%) were under 24 years, and $1166(28.0 \%)$ were over 35 years. Most mothers $(n=$ 3016, $72.0 \%$ ) had completed primary school, with 803

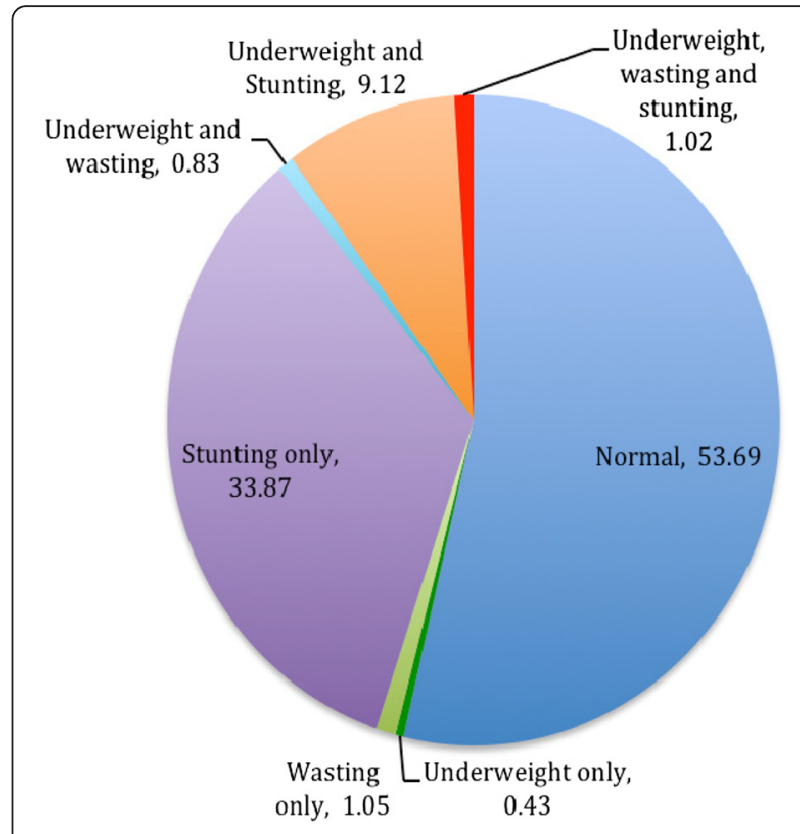

Fig. 1 Relative frequencies of 7 anthropometric categories

(19\%) having no education and 357 (9.0\%) having completed secondary school or higher. Few mothers $(n=$ 374, $9.0 \%)$ were skilled workers, 3385 (81.0 \%) worked outside the home in an unskilled profession, and 415 $(10.0 \%)$ did not work outside the home. Household wealth was approximately evenly distributed across the quintiles; 1848 children (44.2\%) were from households in the bottom two wealth quintiles, $848(20.0 \%)$ were from households in the middle quintile, and 1480 $(35.0 \%)$ were from households in the top two wealth quintiles. Most children were from households in rural areas $(n=3692,88.0 \%)$. More than $50 \%$ of households ( $n=2431,59.7 \%)$ used improved toilets that were not shared, while the remainder had either unimproved or shared toilets. Over half of the children $(n=2181$, $52.7 \%)$ were from households from which it required at least $30 \mathrm{~min}$ to get water, $1787(43.1 \%)$ could access water in less than $30 \mathrm{~min}$, and $167(4.0 \%)$ had water on premises. Half of households $(n=2118,50.7 \%)$ had access to improved water sources.

\section{Univariable analysis of risk factors associated with underweight}

The following child characteristics were associated with an increased risk of being underweight at the $p<0.10$ level: male sex, fever in the previous two weeks, recent deworming treatment, time since the birth of the previous child and small size at birth. Mothers of underweight children were more likely to be over 35 years, to have lower education, to smoke, to be unskilled workers, to have a low BMI and to have had their last child 
Table 2 Univariable analysis of socio-demographic characteristics and underweight status in children under five in Rwanda, DHS 2010

\begin{tabular}{|c|c|c|c|c|}
\hline & $N$ weighted & Underweight & Univariate & \\
\hline & & & $\mathrm{OR}[95 \% \mathrm{Cl}]$ & $p$-value \\
\hline Child characteristics & & & & \\
\hline Underweight & 469 & 11.4 & - & - \\
\hline Child size at birth* age in months & & & & \\
\hline Not small size, $<12$ & 444 & 11.2 & 1 & \\
\hline Small size, $<12$ & 23 & 16.9 & $1.62[0.97,2.70]$ & 0.067 \\
\hline Not small size, $12-23$ & 442 & 11.1 & 1 & \\
\hline Small size, 12-23 & 25 & 19.6 & $1.95[1.23,3.10]$ & 0.005 \\
\hline Not small size, 24-35 & 441 & 11.1 & 1 & \\
\hline Small size, 24-35 & 25 & 18.8 & $1.85[1.18,2.90]$ & 0.008 \\
\hline Not small size, 36-47 & 444 & 11.1 & 1 & \\
\hline Small size, 36-47 & 22 & 19.6 & $1.95[1.14,3.33]$ & 0.015 \\
\hline Not small size, 48-59 & 438 & 11.0 & 1 & \\
\hline Small size, $48-59$ & 28 & 23.2 & $2.45[1.60,3.75]$ & $<0.001$ \\
\hline Child sex & & & & \\
\hline Girls & 2075 & 10.0 & 1 & \\
\hline Boys & 2101 & 12.7 & $1.31[1.06,1.60]$ & 0.010 \\
\hline Breastfeeding & & & & \\
\hline Ever breastfed, not currently breastfeeding & 2025 & 11.7 & 1 & \\
\hline Never breastfed & 12 & 16.4 & $1.48[0.36,6.09]$ & 0.586 \\
\hline Still breastfeeding & 2123 & 11.0 & $0.94[0.78,1.13]$ & 0.495 \\
\hline Fever in last 2 weeks & & & & \\
\hline No & 3481 & 10.7 & 1 & \\
\hline Yes & 693 & 14.7 & $1.43[1.09,1.86]$ & 0.009 \\
\hline Deworming (drugs for intestinal parasites in la & & & & \\
\hline No & 897 & 9.3 & 1 & \\
\hline Yes & 3278 & 12 & $1.33[1.01,1.76]$ & 0.040 \\
\hline Diarrhea in last 2 weeks & & & & \\
\hline No & 3606 & 11.0 & 1 & \\
\hline Yes & 569 & 13.9 & $1.31[1.00,1.72]$ & 0.052 \\
\hline Full vaccinated & & & & \\
\hline No & 1029 & 10.2 & 1 & \\
\hline Yes & 3147 & 11.8 & $1.18[0.92,1.52]$ & 0.191 \\
\hline Birth interval (from previous birth) & & & & \\
\hline Singleton first-born & 1014 & 6.8 & 1 & \\
\hline Singleton birth $<2$ years & 624 & 8.4 & $1.26[0.89,1.80]$ & 0.193 \\
\hline Singleton birth $>=2$ years & 2437 & 13.2 & $2.09[1.59,2.76]$ & $<0.001$ \\
\hline Multiple births & 101 & 31.2 & $6.21[3.55,10.85]$ & $<0.001$ \\
\hline Mother characteristics & & & & \\
\hline Mother age & & & & \\
\hline $15-24$ years & 755 & 6.9 & 1 & \\
\hline $25-34$ years & 2255 & 10.5 & $1.58[1.09,2.28]$ & 0.015 \\
\hline $35-49$ years & 1166 & 16.1 & $2.59[1.79,3.76]$ & $<0.001$ \\
\hline
\end{tabular}


Table 2 Univariable analysis of socio-demographic characteristics and underweight status in children under five in Rwanda, DHS 2010 (Continued)

Mother's highest level of educational

\section{No education \\ Primary \\ Secondary or higher}

Smoking

No

Yes

Body mass index of mother

$$
\begin{aligned}
& <18.5 \text { underweight } \\
& \text { 18.5-24.9 normal weight } \\
& \text { 25.0-29.9 overweight } \\
& >=30 \text { Obesity }
\end{aligned}
$$

Delivered by health care professional

$$
\text { Yes }
$$$$
\text { No }
$$

Number of antenatal care visits

$$
\begin{aligned}
& \text { None } \\
& 1 \\
& 2-3 \\
& 4+
\end{aligned}
$$

Mother occupation

$$
\begin{aligned}
& \text { Not working } \\
& \text { Skilled worker } \\
& \text { Unskilled worker } \\
& \text { Marital status } \\
& \text { Single } \\
& \text { Married }
\end{aligned}
$$$$
\text { Divorced/separated }
$$

Household characteristics

Number of living children

$$
1-3
$$$$
\text { 4+ }
$$

Number of persons in household

$$
\text { 2-3 }
$$$$
4+
$$

Sex of the household head

$$
\begin{aligned}
& \text { Female } \\
& \text { Male }
\end{aligned}
$$

Residence

Urban

Rural

Wealth quintiles

Top 2

Middle
14.7
$6.06[3.22,11.42]$

$<0.001$

$4.60[2.51,8.43]$

$<0.001$

1

1

$1.59[1.00,2.53]$

0.049

$2.52[1.67,3.81]$

$<0.001$

1

$0.51[0.35,0.75]$

0.001

$0.65[0.31,1.35]$

0.245

1

$1.57[1.28,1.94]$

$<0.001$

$1.72[0.61,4.88] \quad 0.306$

$1.10[0.43,2.79] \quad 0.843$

$0.95[0.36,2.46] \quad 0.909$

$2.35[1.33,4.13] \quad 0.003$

1

$2.09[1.33,3.26] \quad 0.001$

$1.09[0.69,1.75] \quad 0.703$

$1.66[0.96,2.87] \quad 0.068$

$1.58[1.27,1.96]$

$<0.001$

$1.61[1.17,2.22]$

0.004

$1.05[0.83,1.33]$

0.654

1

1

$2.00[1.35,2.95]$

0.001

1

$1.58[1.15,2.17]$

0.004 
Table 2 Univariable analysis of socio-demographic characteristics and underweight status in children under five in Rwanda, DHS 2010 (Continued)

\begin{tabular}{|c|c|c|c|c|}
\hline Bottom 2 & 1848 & 14.6 & $2.14[1.66,2.75]$ & $<0.001$ \\
\hline \multicolumn{5}{|c|}{ Toilet is clean upon inspection } \\
\hline Yes & 1442 & 8.7 & 1 & \\
\hline No & 2717 & 12.8 & $1.53[1.21,1.94]$ & $<0.001$ \\
\hline \multicolumn{5}{|l|}{ Type of quality of toilet } \\
\hline Unimproved shared & 203 & 19.4 & $2.17[1.43,3.30]$ & $<0.00$ \\
\hline Improved shared & 575 & 9.2 & $0.91[0.62,1.33]$ & 0.635 \\
\hline Improved not shared & 2431 & 10.0 & 1 & \\
\hline Unimproved not shared & 866 & 15.0 & $1.60[1.24,2.07]$ & 0.001 \\
\hline \multicolumn{5}{|c|}{ Proximity to improved water source } \\
\hline Water on premise & 167 & 5.5 & 1 & \\
\hline$<30$ minutes & 1787 & 11.9 & $2.31[1.22,4.38]$ & 0.010 \\
\hline$>=30$ minutes & 2181 & 11.6 & $2.26[1.20,4.28]$ & 0.012 \\
\hline \multicolumn{5}{|c|}{ Anything done to water to make safe to drink } \\
\hline Yes & 2058 & 9.5 & 1 & \\
\hline No & 2118 & 13.2 & $1.44[1.15,1.80]$ & 0.001 \\
\hline
\end{tabular}

than average" and "very small" to be "small at birth" in this analysis

delivered by an unskilled provider. Households of underweight children were more likely to have more members, more children in the household, to be rural, to fall into a low wealth quintile, to have an unclean, unimproved, or shared toilet and to be $30 \mathrm{~min}$ or more from water. Breastfeeding, vaccination, antenatal care in the previous pregnancy, sex of the head of household and maternal marital status were not associated with underweight status (Table 2).

\section{Risk factors associated with underweight, a multivariable analysis}

In multivariable analysis, we found that children were more likely to be underweight if they were male $(\mathrm{OR}=$ 1.42, $95 \%$ confidence interval (CI): 1.12, 1.79), had a fever in the two weeks prior to survey administration $(\mathrm{OR}=1.45,95 \% \mathrm{CI}: 1.07,1.97)$ or were multiple birth infants compared to the first, single birth $(\mathrm{OR}=4.04$, 95 \% CI: 2.12, 7.71). In an interaction analysis, we found that the effect of small size at birth persisted in all age strata. Children were also more likely to be underweight if their mothers were over 35 compared to those aged 17 to $24(\mathrm{OR}=1.67,95 \% \mathrm{CI}: 1.04,2.70)$; had a BMI under $18.5(\mathrm{OR}=2.62,95 \% \mathrm{CI}: 1.70,4.04)$; had either no education or primary education only $(\mathrm{OR}=3.56,95 \% \mathrm{CI}$ : $1.83,6.95$; OR $=3.49,95 \% \mathrm{CI}: 1.87,6.51$, respectively) compared to secondary education or higher, or were attended by an unskilled provider during their last delivery $(\mathrm{OR}=1.33$, $95 \% \mathrm{CI}: 1.04,1.72)$. Underweight children were more likely to live in households in one of the two lowest wealth quintiles compared to the highest two quintiles (OR = 1.71, 95 \% CI: 1.27, 2.30) (Table 3).

\section{Discussion}

In this analysis of the 2010 RDHS, we found that the prevalence of underweight children in Rwanda was low compared to the neighboring countries of Burundi, Democratic Republic of Congo and Tanzania [3], but considerably higher compared to the developed economies [11]. We identified several child risk factors for being underweight including being male, being small at birth, having fever in the two weeks prior to the survey and being born as a multiple birth infant. Maternal and household risk factors included the mother being 35 years or older, low education level, low maternal BMI, not having the delivery assisted by a health professional and wealth levels in the lowest two quintiles. While the prevalence of underweight children under five is lower in Rwanda compared to other countries in the region, many risk factors for under-nutrition among under five children are the same as those reported in nearby countries: these include fever, mother's nutritional status, mother's education level, household socio-economic status, and accessibility to piped water [8, 12-16]. Importantly, the persistent association between low maternal BMI and child under-nutrition in these studies suggests that intergenerational nutrition plays a strong role in these outcomes.

Among the child-related factors that were associated with being underweight, the only one that could potentially be addressed after a child's birth is recent febrile 
Table 3 Multivariable analysis of risk factors associated with being underweight among children under five in Rwanda, DHS 2010

\begin{tabular}{|c|c|c|c|c|}
\hline & \multicolumn{2}{|l|}{ Full model } & \multicolumn{2}{|l|}{ Reduced model } \\
\hline & OR $[95 \% \mathrm{Cl}]$ & $p$-value & OR $[95 \% \mathrm{Cl}]$ & $p$-value \\
\hline \multicolumn{5}{|l|}{ Child characteristics } \\
\hline \multicolumn{5}{|l|}{ Size at birth* by age in months } \\
\hline Normal, $<12$ & 1 & & 1 & \\
\hline Small, $<12$ & $2.56[1.40,4.69]$ & 0.002 & $2.38[1.32,4.28]$ & 0.004 \\
\hline Not small size, 12-23 & 1 & & 1 & \\
\hline Small size, 12-23 & $1.56[0.84,2.90]$ & 0.161 & $1.36[0.75,2.47]$ & 0.310 \\
\hline Not small size, 24-35 & 1 & & 1 & \\
\hline Small size, 24-35 & $2.49[1.39,4.21]$ & 0.002 & $2.46[1.45,4.19]$ & 0.001 \\
\hline Not small size, 36-47 & 1 & & 1 & \\
\hline Small size, 36-47 & $1.99[1.01,3.90]$ & 0.045 & $2.16[1.13,4.15]$ & 0.020 \\
\hline Not small size, 48-59 & 1 & & 1 & \\
\hline Small size, 48-59 & $2.25[1.29,3.93]$ & 0.004 & $2.27[1.31,3.94]$ & 0.003 \\
\hline \multicolumn{5}{|l|}{ Sex } \\
\hline Boys & $1.42[1.13,1.79]$ & 0.003 & $1.42[1.12,1.79]$ & 0.002 \\
\hline Girls & 1 & & 1 & \\
\hline \multicolumn{5}{|l|}{ Fever in last 2 weeks } \\
\hline No & 1 & & & \\
\hline Yes & $1.44[1.05,1.97]$ & 0.023 & $1.45[1.07,1.97]$ & 0.016 \\
\hline \multicolumn{5}{|c|}{ Received drugs for intestinal parasites in last 6 months } \\
\hline No & 1 & & & \\
\hline Yes & $1.19[0.82,1.74]$ & 0.365 & & \\
\hline \multicolumn{5}{|l|}{ Diarrhea in previous 2 weeks } \\
\hline No & 1 & & & \\
\hline Yes & $1.21[0.86,1.71]$ & 0.274 & & \\
\hline \multicolumn{5}{|c|}{ Birth interval (from previous birth) } \\
\hline Singleton first-born & 1 & & 1 & \\
\hline Singleton birth $<2$ years & $1.12[0.71,1.76]$ & 0.622 & $1.17[0.76,1.82]$ & 0.476 \\
\hline Singleton birth $>=2$ years & $1.46[0.95,2.22]$ & 0.082 & $1.69[1.14,2.51]$ & 0.010 \\
\hline Multiple births & $3.56[1.84,6.86]$ & $<0.001$ & $4.04[2.12,7.71]$ & $<0.001$ \\
\hline \multicolumn{5}{|l|}{ Mother characteristics } \\
\hline \multicolumn{5}{|l|}{ Age } \\
\hline $15-24$ years & 1 & & & \\
\hline $25-34$ years & $1.17[0.73,1.87]$ & 0.506 & $1.17[0.74,1.84]$ & 0.496 \\
\hline $35-49$ years & $1.65[0.97,2.80]$ & 0.066 & $1.67[1.04,2.70]$ & 0.035 \\
\hline \multicolumn{5}{|l|}{ Highest level of educational } \\
\hline No education & $3.14[1.61,6.12]$ & 0.001 & $3.56[1.83,6.95]$ & 0.001 \\
\hline Primary & $3.34[1.78,6.26]$ & $<0.001$ & $3.49[1.87,6.51]$ & $<0.001$ \\
\hline Secondary or higher & 1 & & 1 & \\
\hline \multicolumn{5}{|l|}{ Smoking } \\
\hline No & 1 & & & \\
\hline Yes & $0.89[0.53,1.49]$ & 0.649 & & \\
\hline
\end{tabular}


Table 3 Multivariable analysis of risk factors associated with being underweight among children under five in Rwanda, DHS 2010 (Continued)

\begin{tabular}{|c|c|c|c|c|}
\hline \multicolumn{5}{|l|}{ Body mass index } \\
\hline$<18.5$ & $2.80[1.78,4.40]$ & $<0.001$ & $2.62[1.70,4.04]$ & $<0.001$ \\
\hline $18.5-24.9$ & 1 & & 1 & \\
\hline $25.0-29.9$ & $0.67[0.45,0.99]$ & 0.046 & $0.66[0.44,0.98]$ & 0.040 \\
\hline$>=30$ & $1.16[0.55,2.47]$ & 0.695 & $0.99[0.45,2.16]$ & 0.978 \\
\hline \multicolumn{5}{|l|}{ Delivered by health care professional } \\
\hline Yes & 1 & & 1 & \\
\hline No & $1.26[0.97,1.63]$ & 0.080 & $1.33[1.04,1.72]$ & 0.025 \\
\hline \multicolumn{5}{|l|}{ Occupation } \\
\hline Not working & $2.00[1.03,3.88]$ & 0.041 & & \\
\hline Skilled worker & 1 & & & \\
\hline Unskilled worker & $1.32[0.74,2.35]$ & 0.340 & & \\
\hline \multicolumn{5}{|l|}{ Marital status } \\
\hline Single & 1 & & & \\
\hline Married & $1.06[0.63,1.80]$ & 0.814 & & \\
\hline Divorced/separated & $1.68[0.92,3.08]$ & 0.090 & & \\
\hline \multicolumn{5}{|l|}{ Household characteristics } \\
\hline \multicolumn{5}{|l|}{ Number of living children } \\
\hline $1-3$ & 1 & & & \\
\hline $4+$ & $1.10[0.82,1.48]$ & 0.517 & & \\
\hline \multicolumn{5}{|l|}{ Number of persons in household } \\
\hline $2-3$ & 1 & & & \\
\hline $4+$ & $1.54[1.02,2.32]$ & 0.039 & & \\
\hline \multicolumn{5}{|l|}{ Residence } \\
\hline Urban & 1 & & & \\
\hline Rural & $1.11[0.69,1.78]$ & 0.674 & & \\
\hline \multicolumn{5}{|l|}{ Wealth quintiles } \\
\hline Wealthiest (top two quintiles) & 1 & & & \\
\hline Middle & $1.25[0.85,1.82]$ & 0.252 & $1.32[0.92,1.91]$ & 0.131 \\
\hline Poorest (bottom two quintiles) & $1.47[1.06,2.04]$ & 0.020 & $1.71[1.27,2.30]$ & $<0.001$ \\
\hline \multicolumn{5}{|l|}{ Toilet is clean upon inspection } \\
\hline No & $1.09[0.82,1.45]$ & 0.541 & & \\
\hline Yes & 1 & & & \\
\hline \multicolumn{5}{|l|}{ Type of quality of toilet } \\
\hline Unimproved shared & $1.81[1.09,3.03]$ & 0.023 & & \\
\hline Improved shared & $1.06[0.71,1.60]$ & 0.770 & & \\
\hline Improved not shared & 1 & & & \\
\hline Unimproved not shared & $1.14[0.83,1.55]$ & 0.412 & & \\
\hline \multicolumn{5}{|l|}{ Proximity to improved water source } \\
\hline Water on premise & 1 & & & \\
\hline$<30$ minutes & $1.04[0.47,2.28]$ & 0.926 & & \\
\hline$>=30$ minutes & $0.90[0.41,1.97]$ & 0.788 & & \\
\hline
\end{tabular}


Table 3 Multivariable analysis of risk factors associated with being underweight among children under five in Rwanda, DHS 2010 (Continued)
Anything done to water to make safe to drink
Yes
1
No
$1.24[0.97,1.60]$
0.088

*Women were asked, when the child was born "was he/she very large, larger than average, average, smaller than average, or very small?" We considered "smaller than average" and "very small" to be "small at birth" in this analysis

illness. The relationship between child nutrition and infection is bidirectional [17]. Being underweight increases the likelihood of febrile illness because malnutrition suppresses immunity to the culprit infectious agent [18]. Conversely, acute infection can lead to acute weight loss through increases in metabolic demand, impaired nutrient absorption or anorexia [3, 12]. Evidence exists in support of various interventions to improve malnutrition in children on the population-level, including increasing dietary intake following infection to hasten catch up growth [19-21] controlling infectious diseases [22, 23] and improving diets to prevent infection [22, 24]. However, given this cross-sectional study design, we cannot differentiate the direction of the relationship between underweight status and acute infection for the children included in this study. As such, the best interventions for tackling this vicious cycle of malnutrition and infection in Rwanda are unclear. A study based on data from 25 African DHSs found that non-singletons tend to be more malnourished than singletons [25]. Families with multiple births should be considered among the primary target for interventions designed to improve child nutrition [26].

Our finding that maternal education and nutritional status were correlated with a child's nutritional status is consistent with previous reports [16]. One previous study estimating contributions of different factors to the burden of under-nutrition attributed $43 \%$ of the reduction in the prevalence of underweight children between 1970 and 2005 in developing countries to increases in women's secondary education [14]. Previous studies have shown that women with secondary education are better informed about optimal child care practices [8], have better practices in terms of hygiene [27, 28], feeding [18] and childcare during illness [18, 21, 22], have a greater ability to use the health system [29], are more empowered to make decisions [28] and are more likely to have financial resources to care for and feed children [18]. There has been a slight increase in the percentage of women who have completed secondary education in Rwanda, from $1.2 \%$ in 2005 [30] to $2.8 \%$ in 2010 [10], and we hypothesize that further gains in women's education may translate into improved child nutrition outcomes [7, 31, 32].

Although low maternal BMI has repeatedly been shown to be associated with poor child nutrition outcomes, it is unclear if this reflects the impact of poor nutrition on a mother's ability to care for her children or if it is the result of residual confounding by economic status [13].

\section{Limitations}

This study has several limitations that should be considered when interpreting the results. As this is a crosssectional survey study, we are unable to draw causal conclusions about risk factors that lead to children being underweight. Although many of the associations we found are well established in literature and are biologically plausible, there is much less data on the impact of specific interventions designed to address these factors. In addition, some important factors were not measured in the DHS, including household food availability, which has been identified by UNICEF as an important determinant of child under-nutrition [3]. Also, even though underweight combines both stunting and wasting; underweight cannot show the extent to which a child is stunted or wasted, further analysis for risk factors associated with stunting and wasting may inform more the policy making.

\section{Conclusion}

Rwanda was one of the first countries to achieve MDG 1. However, even within Rwanda's context of rapid reduction, the prevalence of underweight children remains high. Several child risk factors for being underweight were identified, including being male, being small at birth, having fever in the two weeks prior to survey administration, and being born as a multiple. Maternal and household risk factors included the mother being 35 years or older, low maternal education level, low maternal BMI, not having the delivery assisted by a health professional and wealth levels in the lowest two quintiles. These risk factors highlight the characteristics of children who remain vulnerable to under-nutrition in Rwanda and who could benefit from both nutrition specific interventions such as Rwanda's one cup of milk per child program [33, 34], breastfeeding, complementary feeding, provision of food supplements, and micronutrient interventions [22] and nutrition sensitive interventions such as poverty reduction, social protections, women's empowerment, measures to boost agricultural production [35], social protection, and safety nets [24]. Because the impact of individual and combined interventions is not 
well established, we recommend that this should be studied to establish the contribution of each intervention and provide evidence for the most effective strategies.

\section{Abbreviations}

BMl, body mass index; Cl, Confidence Interval; MDG, Millennium Development Goal; OR, Odds Ratio; RDHS, Rwanda Demographic and Health Survey; SD, standard deviation; UNICEF, the United Nations Children's Fund; WAZs, weight-for-age Z scores

\section{Acknowledgements}

The authors would like to express their gratitude to Dr. Vedaste Ndahindwa and Prof. Jeanine Condo at the University of Rwanda - College of Medicine and Health Sciences - School of Public Health (UR-CMHS-SPH) for their support in data preparation and analysis and to Kevin Savage from Harvard Medical School for manuscript editing.

\section{Funding}

The first author, AM, attended a training in survey data analysis funded by the African Health Initiative of the Doris Duke Charitable Foundation and facilitated by BLHG and DRT. This manuscript was developed in a training program led by Rwandan Human Resources for Health faculty, and thus has been supported by the President's Emergency Plan for AIDS Relief (PEPFAR) through the US Centers for Disease Control and Prevention under the terms of the grant \# 3U2GPS001891-03 W1.

\section{Availability of data and materials}

RDHS data are freely and publicly available to registered users with permission at http://dhsprogram.com/data/.

\section{Authors' contributions}

The authors' responsibilities were as follows: AM, conceived the research question, designed the protocol, implemented data analysis and wrote the manuscript; BLHG, DRT, MM contributed to data analysis and guided manuscript writing and review; PB and LN revised the protocol, data analysis and manuscript. All authors read and approved the final manuscript.

\section{Competing interests}

The authors declare that they have no competing interests.

\section{Consent for publication}

Not applicable.

\section{Ethics approval and consent to participate}

The Rwandan Ministry of Health Institutional Review Board granted ethics approval for the RDHS data collection. Informed consent from each respondent was obtained prior to survey administration. This is a secondary analysis of this data and all data were deidentified before receipt by investigators on this team.

\section{Author details}

'University of Rwanda School of Public Health, P.O. Box: 3538, Kigali, Rwanda. ${ }^{2}$ Department of Global Health and Social Medicine, Harvard Medical School, Boston, MA, USA. ${ }^{3}$ Partners In Health, Rwinkwavu, Rwanda. ${ }^{4}$ Rwanda Biomedical Center, Ministry of Health, Kigali, Rwanda. ${ }^{5}$ Bill \& Melinda Gates Foundation, Seattle, WA, USA. ${ }^{6}$ Department of Epidemiology, Harvard School of Public Health, Boston, MA, USA.

Received: 10 October 2015 Accepted: 25 June 2016

Published online: 08 July 2016

\section{References}

1. Black RE, Allen LH, Bhutta ZA, Caulfield LE, de Onis M, Ezzati M, et al. Maternal and child undernutrition: global and regional exposures and health consequences. Lancet [Internet]. 2008;371(9608):243-60. Available from: http://www.ncbi.nlm.nih.gov/pubmed/18207566.

2. UN Inter-agency Group for Child Mortality Estimation. Levels and trends in child mortality. 2013 [cited 2014 Jan 29]; Available from: http://www.who. int/entity/maternal_child_adolescent/documents/levels_trends_child_ mortality_2013.pdf?ua=1.
3. Unicef. Improving child nutrition. The achievable imperative for global progress [Internet]. 2013. 1-132 p. Available from: http://www.unicef.org/gambia/ Improving_Child_Nutrition_-_the_achievable_imperative_for_global_progress.pdf.

4. de Onis M, Blössner M, Borghi E, Frongillo EA, Morris R. Estimates of global prevalence of childhood underweight in 1990 and 2015. JAMA. 2004; 291(21):2600-6.

5. Caulfield LE, Richard S a, Rivera I a, Musgrove P, Black RE. Stunting, Wasting, and Micronutrient Deficiency Disorders. In: Disease Control Priorities in Developing Countries [Internet]. 2006. p. 551-67. Available from: http:// www.ncbi.nlm.nih.gov/books/NBK11761/pdf/Bookshelf_NBK11761.pdf.

6. Klaver W. Underweight or stunting as an indicator of the MDG on poverty and hunger Wijnand Klaver. African Stud Cent. 2010;1-41. https:// openaccess.leidenuniv.n//bitstream/handle/1887/16313/ASC-0752876682793-01.pdf? sequence $=2$.

7. Pramod Singh GC, Nair M, Grubesic RB, Connell FA. Factors associated with underweight and stunting among children in rural Terai of eastern Nepal. Asia Pac J Public Health [Internet]. 2009;21 (2):144-52. Available from: http:// aph.sagepub.com/cgi/content/long/21/2/144.

8. Samuel Oyekale A. Factors explaining acute malnutrition among underfive children in Sub-Sahara Africa (SSA). Life Sci J [Internet]. 2012;9(4): 2101-7. Available from: http://www.lifesciencesite.com/lsj/life0904/314_ 11976life0904_2101_2107.pdf.

9. ONAPO ONP. Enquête Démographique et de Santé 1992. 11785 Beltsville Drive, Calverton; 1992.

10. National Institute of Statistics of Rwanda (NISR) [Rwanda], Ministry of Health (MOH) [Rwanda] and II. Rwanda Demographic and Health Survey 2010. 2011.

11. United Nations Children's Fund, Organization WH, The World Bank. UNICEFWHO- World Bank. Joint Child Malnutrition Estimates. Africa. 2012.

12. Weisz A, Meuli G, Thakwalakwa C, Trehan I, Maleta K, Manary M. The duration of diarrhea and fever is associated with growth faltering in rural Malawian children aged 6-18 months. Nutr J. 2011;10(1):25.

13. McDonald CM, Kupka R, Manji KP, Okuma J, Bosch RJ, Aboud S, et al. Predictors of stunting, wasting and underweight among Tanzanian children born to HIV-infected women. Eur J Clin Nutr [Internet]. 2012;66(11):1265-76. Available from: http://www.pubmedcentral.nih.gov/articlerender. fcgi?artid=3491141\&tool=pmcentrez\&rendertype=abstract.

14. Janet Byaruhanga (AU) et.al. Cost of Hunger Study in Rwanda: Child Undernutrition in Rwanda Implications for Achieving Vision 2020, Kigali, 3rd National Food \&Nutrition Summit 2014. 3rd National Food \& Nutrition Summit 2014. 2014.

15. Balk D, Storeygard A, Levy M, Gaskell J, Sharma M, Flor R. Child hunger in the developing world: An analysis of environmental and social correlates. Food Policy [Internet]. 2005;30(5-6):589. Available from: http://linkinghub. elsevier.com/retrieve/pii/S0306919205000886.

16. Alasfoor D, Traissac P, Gartner A, Delpeuch F. Determinants of persistent underweight among children, aged 6-35 months, after huge economic development and improvements in health services in Oman. J Heal Popul Nutr. 2007;25(3):359-69.

17. Dewey KG, Mayers DR. Early child growth: How do nutrition and infection interact? Matern Child Nutr. 2011;7 Suppl 3:129-42.

18. Gulati J. Child Malnutrition: Trends and Issues. Anthropologist [Internet]. 2010;12(2):131-40. Available from: http://www.krepublishers.com/02Journals/T-Anth/Anth-12-0-000-10-Web/Anth-12-2-000-10-Abst-PDF/Anth12-2-131-10-513-Gulati-J-K/Anth-12-2-131-10-513-Gulati-J-K-Tt.pdf.

19. Food and Agricultural Organisation. Energy and Protein Requirements [Internet]. World Health Organisation Technical Report Series. 1985. Available from: http://www.fao.org/docrep/003/aa040e/AA040E10.htm.

20. Becker S, Black RE, Brown KH. Relative effects of diarrhea, fever, and dietary energy intake on weight gain in rural Bangladeshi children. Am J Clin Nutr. 1991;53(6):1499-503.

21. Iannotti LL, Dulience SJL, Green J, Joseph S, François J, Anténor M-L, et al. Linear growth increased in young children in an urban slum of Haiti: a randomized controlled trial of a lipid-based nutrient supplement. Am J Clin Nutr [Internet]. 2014;99(1):198-208. Available from: http://ajcn.nutrition.org/ content/99/1/198.short.

22. Bhutta ZA, Ahmed T, Black RE, Cousens S, Dewey K, Giugliani E, et al. What works? Interventions for maternal and child undernutrition and survival. Lancet. 2008:371:417-40.

23. Salam RA, Maredia H, Das JK, Lassi ZS, Bhutta ZA. Community-based interventions for the prevention and control of helmintic neglected tropical diseases. Infect Dis Poverty. 2014;3(1):1-17. 
24. Bhutta ZA, Das JK, Rizvi A, Gaffey MF, Walker N, Horton S, et al. Evidencebased interventions for improvement of maternal and child nutrition: What can be done and at what cost? Lancet. 2013;382:452-77.

25. Gebremedhin S. Multiple Births in Sub-Saharan Africa: Epidemiology, Postnatal Survival, and Growth Pattern. Twin Res Hum Genet [Internet]. 2014 Dec 29 [cited 2015 Feb 4];(October):1-8. Available from: http://www.ncbi.nlm.nih.gov/ pubmed/25544149.

26. Fenske N, Burns J, Hothorn T, Rehfuess EA. Understanding child stunting in India: A comprehensive analysis of socio-economic, nutritional and environmental determinants using additive quantile regression. PLoS One. 2013;8(11):e78692. doi:10.1371/journal.pone.0078692.

27. Smith LC, Haddad L. Explaining Child Malnutrition in Developing Countries A Cross-Country Analysis. Who. 2000;25(3):1-112.

28. Keats A. Women's Schooling, Fertility, and Child Health Outcomes: Evidence from Uganda's Free Primary Education Program. 2014; Available from: http://akeats.faculty.wesleyan.edu/files/2014/02/Uganda_paper_Keats_ 14feb14.pdf.

29. Sunguya BF, Poudel KC, Mlunde LB, Urassa DP, Yasuoka J, Jimba M. Poor nutrition status and associated feeding practices among HIV-positive children in a food secure region in tanzania: A call for tailored nutrition training. PLoS One. 2014;9(5):e98308. Public Library of Science.

30. National Institute of Statistics Rwanda. Rwanda Demographic and Health Survey 2005: Key Findings. 2006.

31. Subramanian SV, Ackerson LK, Smith GD. Parental BMI and childhood undernutrition in India: an assessment of intrauterine influence. Pediatrics [Internet]. 2010;126(3):e663-71. Available from: http://www.ncbi.nlm.nih.gov/ pubmed/20713473.

32. Bailey RC, Kamenga MC, Nsuami MJ, Nieburg P, St Louis ME. Growth of children according to maternal and child HIV, immunological and disease characteristics: a prospective cohort study in Kinshasa, Democratic Republic of Congo. Int J Epidemiol [Internet]. 1999;28(3):532-40. Available from: http://ije.oxfordjournals.org/cgi/content/long/28/3/532.

33. Rwanda Agriculture Board. Nutrition Program- Rwanda Agriculture Board [Internet]. Available from: http://rab.gov.rw/departments/crop-productionfood-security/.

34. Misbah Sheikh and Cyriaque Ngoboka. Agakono k'umwana [Internet]. 2015. Available from: http://www.unicef.org/rwanda/reallives_8383.html.

35. Security F, Plan I. Comprehensive Africa Agriculture Development Programme (CAADP) East and Central Africa Regional CAADP Nutrition Program Development Workshop Nutrition Country Paper - Rwanda February 2013. 2013.

\section{Submit your next manuscript to BioMed Central and we will help you at every step:}

- We accept pre-submission inquiries

- Our selector tool helps you to find the most relevant journal

- We provide round the clock customer support

- Convenient online submission

- Thorough peer review

- Inclusion in PubMed and all major indexing services

- Maximum visibility for your research

Submit your manuscript at www.biomedcentral.com/submit

) Biomed Central 